\title{
Acute non puerperal inversion of uterus with large submucous fibroid
}

\author{
Vinita Singh* \\ Department of Obstetrics and Gynaecology, AIIMS Raipur, Tatibandh, Raipur, Chattisgarh-492001, India
}

Received: 10 May 2016

Revised: 03 June 2016

Accepted: 04 June 2016

\section{*Correspondence:}

Dr. Vinita Singh,

E-mail: ddvinitasingh@gmail.com

Copyright: $\odot$ the author(s), publisher and licensee Medip Academy. This is an open-access article distributed under the terms of the Creative Commons Attribution Non-Commercial License, which permits unrestricted non-commercial use, distribution, and reproduction in any medium, provided the original work is properly cited.

\begin{abstract}
Non-puerperal uterine inversion (NPUI) is rare and is usually precipitated by tumors sited at the fundus of the uterus which exert traction force to cause the inversion Acute inversion is more dramatic and characterized by severe pain and bleeding and patient might go into shock whereas chronic is insidious with irregular bleeding and vaginal discharge. In this paper, we present a case of a 55years old woman who presented with retention of urine and menorrhagia for 3 months followed by acute NPUI secondary to a submucous fundal fibroid due to which patient went into sudden shock. Finally laparotomy had to be done followed by total abdominal hysterectomy and bilateral salpingo-oophorectomy.
\end{abstract}

Keywords: NPUI, Sub mucous fibroid, Inversion

\section{INTRODUCTION}

NPUI is around $1 / 6$ of all inversions. ${ }^{1}$ Non-puerperal uterine inversion can also be classified into acute and chronic based on the onset and evolution. The acute is more dramatic and characterised by severe pain and haemorrhages whereas the chronic is insidious and characterised by pelvic discomfort, vaginal discharge, irregular vaginal bleeding and anaemia. ${ }^{1-2}$ The diagnosis is said to be difficult and requires high index of suspicion especially when the inversion is partial. ${ }^{3-4}$ It occurs chiefly when the uterus acts to expel a submucous leiomyomas with fundal attachment. ${ }^{5}$ The patients of non-puerperal uterine inversion usually presents with vaginal discharge, irregular or heavy uterine bleeding or with urinary problems. Patients also complain of pelvic discomfort and labor pain when tumour is being expelled. The present case was an acute non-puerperal uterine inversion due to a growing submucous Myoma. Our patient also presented with shock, which is sometimes associated with puerperal uterine inversion.

\section{CASE REPORT}

A 55 year old P3L3 female who got admitted in morning through OPD in gynecology department of AIIMS Raipur with complain of continuous bleeding since 3 months and retention of urine for 4-5 days and came with catheter in situ. On per abdomen examination uterus was 14 weeks size and large fibroid polyp of $7 \mathrm{X} 7 \mathrm{~cm}$ was seen filling the vagina but cervical rim was not felt. $\mathrm{P} / \mathrm{V}$ examination was not possible. On P/R examination uterus was felt but exact size could not be assessed and no other separate mass could be delineated. Same night of admission spontaneous inversion of uterus took place and patient went into shock for which resuscitation with 3 units of blood was done. Patient was fully investigated and preanaesthetic check-up was done. In the meanwhile dressing was done twice daily with betadine solution as the mass was infected and necrosis had started. After 6 days of this episode the patient was posted in operation theatre. We intended to perform a vaginal myomectomy with the goal of restoring the inverted uterus to its normal anatomic state prior to proceeding with a vaginal 
hysterectomy. Therefore vaginal removal of the tumor was attempted but it was sessile and necrotic and no distinct plane could be delineated separately with the endometrial lining hence only incomplete removal was possible. Under general anaesthesia we attempted to replace the uterus but in vain. Therefore we decided to open the abdomen by pfannensteil incision and uterus was not visible with fallopian tube, round and infundibulopelvic ligament was inverted into the fundal dimpling. The constricting ring was too tight and by using the Huntington procedure reinversion was unsuccessful so Haultain abdominal approach-vagino cervical ring is incised posterior and carried up the posterior wall of uterus until it can be re-inverted. ${ }^{6}$ Bladder was taken care of and pushed down. Abdominal hysterectomy and bilateral salpingo-oophorectomy was done. Together per-operatively and postoperatively 4 more units of blood was transfuse and kept on higher antibiotics .Postoperatively there was gaping of wound on day 7 for which dressing and resuturing was done. Patient doing fine and no problems were identified on two postdischarge clinic visits.

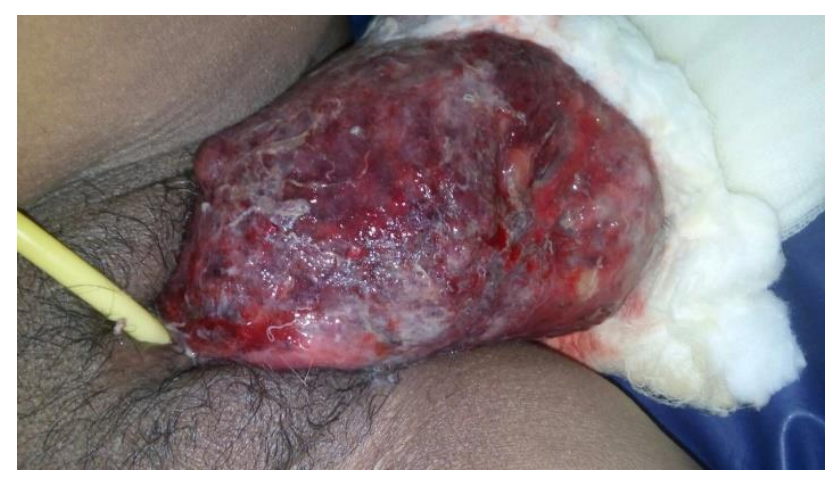

Figure 1: Non puerperal acute inversion of uterus with large submucous fundal fibroid front view.

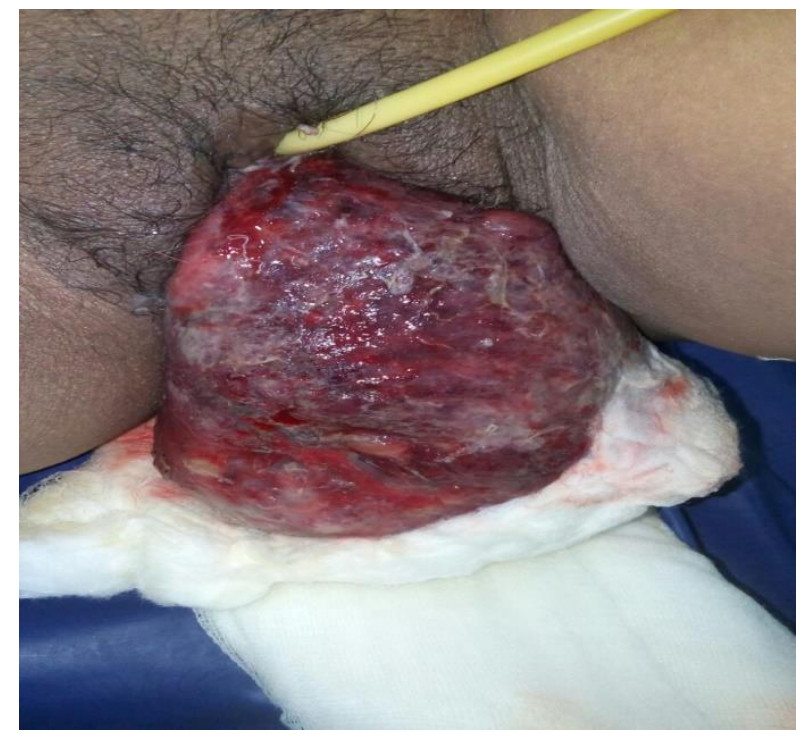

Figure 2: Non puerperal acute inversion of uterus with large submucous fundal fibroid lateral view.

\section{DISCUSSION}

Acute puerperal uterine inversion is a rare but potentially life-threatening complication in which the uterine fundus collapses within the endometrial cavity. ${ }^{7}$ Uterine inversion is suspected when a tumor is palpable in the vagina but the uterine fundus is not palpable by a pelvic examination. In the present case extruded tumor was observed through the vulva but a pelvic examination was not possible. Diagnosis of inversion as such can be made by clinical examination-mass coming out per vagina with negative probe test and recto abdominal method is helpful. ${ }^{8}$ In USG-indentation of fundal area and depressed longitudinal groove from the uterus to centre of the inverted uterus may be seen. USG may show 'target sign' due to fluid within the space between inverted uterus and vaginal wall. ${ }^{9}$ In MRI-a 'U'-shaped uterine cavity and a thickened and inverted uterine fundus on a sagittal image and a Bull's eye configuration on an axial image may be seen. T2-weighted MRI is suggested to be of more importance. ${ }^{10}$ Many surgical techniques have been described, abdominally those of Huntington and Haultain, and vaginally those of Kustner and Spinelli. ${ }^{11,12}$ When the patient no longer wishes to retain the uterus, hysterectomy is offered, usually by the vaginal route. In cases of acute inversion, comprises of blood replacement, antibiotics, and careful monitoring are necessary for successful perioperative management. Treatment of the inversion depends on the stage and associated pathology. The prognosis depends on the initial diagnosis and the stage of disease. ${ }^{13}$

\section{CONCLUSION}

Non-puerperal uterine inversion is an uncommon entity that we gynaecologists will rarely encounter is difficult to manage. Suspicion from clinical features like the presence of a tumor protruding from vagina or vulva, we must consider uterine inversion followed by USG and MRI leads to its diagnosis. However definite diagnosis is sometimes made by examination under anaesthesia or by intra operative findings. Its treatment is surgical (abdominal or vaginal).

\section{Funding: No funding sources \\ Conflict of interest: None declared \\ Ethical approval: Not required}

\section{REFERENCES}

1. Krenning RA, Dorr PJ, De Groot WH. Nonpuerperal uterine inversion. Case report. Br J Obstet Gynaecol. 1982;8(9):247-9.

2. Gowri V. Uterine inversion and corpus malignancies. A historical review. Obset Gynecol Surv. 2000;55:703-7.

3. Takano K, Ichikawa Y, Tsunoda H, Nishida M. et al. Uterine inversion caused by uterine sarcoma: a case report. Jpn Clin Oncol. 2001;31(1):39-42. 
4. Kopal S, Seckin NC, Turhan NO. Acute uterine inversion due to a growing submucous myoma in an elderly woman: case report. Eur J Obstet Gynecol Reprod Biol. 2001;99:118-20.

5. Lai FM, Tseng P, Yeo SH, Tsakok FH. Nonpuerperal uterine inversion: a case report. Singapore Med J. 1993;34:466-8.

6. Haultain F. The treatment of chronic uterine inversion by uterine hysterotomy. BMJ. 1901;2:974-80.

7. Hostetler DR, Bosworth MF. Uterine inversion: a life-threatening obstetric emergency. J Am Board Fam Pract. 2000;13(2):120-3.

8. Deka G, Das GC, Gautam H. Non puerperal uterine inversion with fibroid polyp: a case report. The New Indian Journal of OBGYN. 2016;2(2):121-4.
9. Kuntal AR, Pravin SP. Complete uterine inversion: An unusual yet Crucial Sonographic Diagnosis. J Ultrasound Med. 2009;28:1719-22.

10. Lewin JS, Bryan PJ. MR imaging of uterine inversion. J Comput Assist Tomogr. 1989;13:357-9.

11. Rocconi R, Huh WK, Chiang S. Postmenopausal uterine inversion associated with endometrial polyps. Obstet Gynecol. 2003;102:521-3.

12. Spinelli PG. Inversion of the uterus. Riv Ginec Contemp. 1897;11:567-70.

13. Gowri V. Uterine inversion and corpus malignancies: a historical review. Obstet Gynecol Surv. 2000;55:703-7.

Cite this article as: Singh V. Acute non puerperal inversion of uterus with large submucous fibroid. Int $\mathbf{J}$ Reprod Contracept Obstet Gynecol 2016;5:2460-2. 